\title{
LA AUSENCIA AMBIGUA: HACIA UN SIGLO SIN INTELECTUALES
}

\section{AMBIGUOUS ABSENCE: A CENTURY WITH NO MASTERS}

\author{
Francisco A. Laca Arocena*
}

RESUMEN

El artículo constata una creciente pérdida de influencia de los intelectuales en la esfera pública, atribuyendo en parte el desprestigio de la figura del "maestro" a las biografías cambiantes de no pocos de ellos a lo largo del pasado y muy conflictivo siglo XX pero, sobre todo, al desprestigio de los historicismos a los que muchos de ellos sirvieron. Se argumenta que estos historicismos fallidos a los que tantos recursos, tiempo y, sobre todo, vidas humanas se sacrificaron probablemente estén siendo sustituidos por nuevos "historicismos menores" tales como los nacionalismos identitarios. Se propone, siguiendo a Karl Popper el recurso a una ingeniería social basada en el método científico de ensayo-error que solo permiten las organizaciones realmente democráticas $y$, por último, se argumenta en favor de la benevolencia como valor laico y no partidista de moderación de los posible excesos en aras de la eficacia en los que dicha ingeniería social puede incurrir.

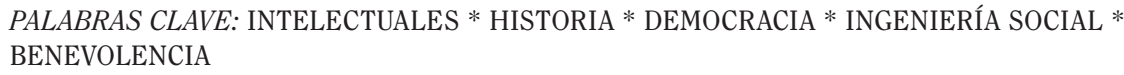

\section{ABSTRACT}

The article confirms a growing loss of influence from intellectuals in the public eye partially attributed to the changing biographies from the disparaged figure of 'master' during the past and conflicted $20^{\text {th }}$ century but, most of all, to the run down of historicisms that many of them served. It is discussed here that these failed historicisms, to which many resources, time and human lives were sacrificed, are probably being replaced by new 'minor historicisms' such as the identity nationalisms. Following Karl Popper, it is proposed here to apply in the society a social engineering based on the scientific method of essay-and-error that only truly democratic organizations allow, and finally, it is discussed in favour of benevolence as a laic and no partisan value of moderation from possible excesses in efficacy search in which this social engineering may incur.

KEY WORDS: INTELLECTUALS * HISTORY * DEMOCRACY * SOCIAL ENGINEERING * BENEVOLENCE

Universidad de Colima y Archivo Histórico

Municipal de Colima, México.

flarocena@gmail.com 


\section{INTRODUCCIÓN}

Era ya un estribillo en las últimas décadas del pasado siglo y se estima un fait accompli en el inicio de este nuevo siglo la casi desaparición de los intelectuales en la esfera pública o, dándole más pompa al concepto, la ausencia de maestros. Ya no hay maestros, se nos dice y repite acompañando tal constatación del tono de desánimo contenido que se supone debe acompañar a toda orfandad lamentada. Después, algunos de nosotros intentamos rellenar ese vacío rememorando retratos venerados en la galería de los maestros ausentes. Habría un amplio consenso en los primeros retratos de tal galería. Montaigne y Goethe fueron espíritus serenos, distantes en el tiempo gozan del beneficio de no haber tenido que nadar en las mareas sucias del pasado siglo. Voltaire parecería poder gozar del beneficio de similar distancia temporal pero fue lo suficientemente rebelde y combativo contra la intolerancia $y$ su hija la injusticia para no provocar aún en nuestros días fuertes filias y fobias. Muchos de quienes persiguieron a Voltaire viven todavía entre nosotros, le perseguirían hoy con el mismo odium teologico. A medida que nos adentramos en el pasado siglo, la elección de maestros se torna más partisana, el enfrentamiento aparece $y$ el consenso en torno a uno $u$ otro nombre disminuye. Ya no estamos ante fríos retratos de cámara de los siglos XVI al XVIII: Montaigne, Locke, Hobbes, Diderot, Goethe, Rousseau, etc. Estamos ante fotos de personas casi contemporáneas a nosotros que convivieron con acontecimientos desgarradores en los que el siglo Xx fue rico hasta el exceso, corroborando con creces la advertencia de Trostky de que quien quisiera una vida tranquila no debería haber nacido en él (Berlin, 2000: 75). Un siglo que forzó a los intelectuales como forzó al hombre $y$ a la mujer de la calle a tomar partido $y$ con no poca frecuencia a cambiar de partido al ritmo en ocasiones acelerado en que cambiaban las situaciones. Probablemente, una de las causas mayores del descrédito actual de los intelectuales nace de las biografías cambiantes de no pocos de ellos. Los hombres y mujeres de la calle, anónimos, tienen como primera tarea su personal supervivencia en las condiciones menos conflictivas posibles sirviendo con ello a la protección de sus seres allegados, sacrificar a esto cualquier coherencia en sus posiciones públicas parece excusable porque en un tiempo difícil una generación en la que todos se empeñasen en ser héroes no tendría probablemente descendencia. Del intelectual, por el contrario, se espera constancia en su discurso, como al faro se le exige luminosidad inamovible. Un faro que se moviese no permitiría al marino referenciar con precisión la distancia de la costa. Esta inmutabilidad en el discurso $y$ en las posiciones públicas de un intelectual la llamamos coherencia y su carencia, la incoherencia, se ha estimado tan descalificadora en el intelectual como la cobardía en el soldado. ¿Es realista esta exigencia en un mundo tan cambiante como el presente? ¿Más importante aún, nos es útil una veleta fija que no oscilase cuando cambia el viento de la historia empeñada en testimoniar que el viento sopla siempre en la misma dirección? Además de la coherencia, se atribuye al intelectual una inteligencia benevolente, esto es una inteligencia fuera de lo común para discriminar caminos en la selva de la historia, que por amor a sus semejantes elegirá el camino que conduzca, a la mayor felicidad posible para el mayor número posible de ellos, (y con esta expresión no estamos aludiendo aquí específicamente a la doctrina de Bentham conocida como utilitarismo). Coherencia, inteligencia y benevolencia (buena voluntad) constituyen una tríada que si no agota el campo del quehacer de un maestro, de un líder intelectual, parecen haber marcado siempre un mínimo exigible a quien se tomase por tal o aceptase que otros así le considerasen. La realidad zigzagueante y particularmente violenta del pasado siglo, el siglo más violento en la historia conocida de nuestra especie, ha dejado en las opiniones públicas mal parada la figura otrora muy respetable del intelectual.

INTELIGENCIA-BENEVOLENCIA: UN BINOMIO FALLIDO

Desde la sustitución, al menos en la civilización Occidental, del pensamiento mítico-religioso por el método científico, de 
las tres conocidas preguntas kantianas la primera $y$ la tercera se dirigen habitualmente en nuestros días al experto científico. Qué podemos saber y qué podemos esperar de la evolución económica en medio de una crisis de recesión, del calentamiento global o del control de una determinada pandemia, es algo que preguntamos al economista, al físico $y$ al biólogo antes que a un afamado novelista o a un profesor de filosofía. Es la segunda pregunta kantiana respecto a qué debemos hacer la que tradicionalmente se ha dirigido a los intelectuales. Por supuesto, también a los científicos se les pregunta qué se debería hacer para acelerar la salida de una crisis económica o intentar revertir el calentamiento global, pero es esta cuestión del deber hacer referida al plano de la acción política, de los proyectos sociales, la tradicional demanda de una guía de navegación que ante el desconcierto de su época cada generación ha dirigido a sus intelectuales. Maestros a quienes se juzgaba depositarios de una aguda inteligencia para descifrar la realidad de un mundo crecientemente complejo $y$, sobre todo, de rigor ético $y$ buena voluntad para discriminar el más justo de los cursos posibles a la acción. Es un supuesto ciertamente ficticio, aunque muy arraigado entre los humanos, que la elevada inteligencia se acompaña necesariamente de rigor ético y hasta de benevolencia. Probablemente, hay una necesidad psicológica de creer tal cosa ante el lógico temor que produce una gran inteligencia sin frenos morales. Ejemplos de muy aguda inteligencia fueron los físicos que trabajando coordinados por Oppenheimer nos regalaron a los humanos la pesadilla atómica que se estrenó en Hiroshima. El propio Oppenheimer, en parte por razones morales pero sobre todo por conflictos íntimos, derivados de su personalidad muy compleja y neurótica (Pais, 2006) se negará pocos años después de Hiroshima a coordinar el proyecto de fabricar la bomba termonuclear de hidrógeno, su colega el físico húngaro Teller retomó con gusto el encargo. El proyecto que colocó al primer hombre en la luna fue coordinado para el gobierno estadounidense por el ingeniero alemán Werner Von Braun quien dos décadas antes fabricaba para Hitler las bombas volantes v1 y v2. Aquellas bombas volantes se fabricaron en "Dora", una monstruosa fábrica subterránea donde de 50000 prisioneros trabajando en condiciones de esclavitud fallecieron 20000 de hambre $y$ malos tratos. Se dirá que estas personas de indiscutible inteligencia eran "simples científicos", no intelectuales comprometidos con la justicia de las causas, no eran maestros en el sentido que aquí damos a este elevado concepto. Concedemos que Oppenheimer, Teller, Von Braun, $y$ no olvidemos al matemático y estratega Von Neuman en cualquier lista de elevadas inteligencias frías $y$ deshumanizadas, no pretendieron ser maestros morales ni fueron tomados por nadie como tales, sin embargo, su muy elevada inteligencia es incuestionable $y$ esta no se acompañaba de ese rigor ético ni esa benevolencia que el prejuicio al que aludíamos gusta atribuir a las personas inteligentes. La evidencia de que una inteligencia elevada no nos dice nada por sí misma de la calidad humana de su poseedor parece bastante consistente. Por supuesto que otros científicos fueron ejemplos públicos de una muy elevada inteligencia $y$ al mismo tiempo un firme compromiso ético, por ejemplo militando por la paz y la tolerancia. Einstein sería ejemplo indiscutible de ello, pero nadie creería seriamente que el descubridor de la Teoría de la Relatividad fuera junto con Russell uno de los militantes pacifistas más activos de su época porque ambos sabían mucha matemática, no sabían menos Teller o Von Neuman.

Pasemos de los científicos a los intelectuales, aquellos que como la etimología de la palabra sugiere hacen de la inteligencia, se supone que de su buen uso, su oficio. A estos, a diferencia de los científicos, les ha sido siempre exigible una ética si no tan imperativa como la kantiana al menos una disposición a la justicia que excluya el oportunismo, la mentira interesada $y$, sobre todo, la agresividad o el ánimo persecutorio.

En 1919, el joven Martin Heidegger comenzó a trabajar como ayudante del profesor Edmund Husserl con cuyo apoyo obtendría en 1923 su primer nombramiento docente. Cuando en 1928 el maestro se jubila Heiddeger le sustituye en su cátedra en Friburgo, el discípulo debe al maestro todo menos su 
genio (Steiner, 2004: 84). Cuando los nazis toman el poder en 1933, Husserl de origen judío y cuya esposa era judía comienza a padecer limitaciones y acosos, mientras Heidegger cuyas simpatías por el nazismo eran previas a la toma del poder por Hitler (Steiner, 2004) es nombrado Rector de la Universidad de Friburgo. Algunos discípulos y admiradores del Heidegger filósofo han pretendido excusar su colaboracionismo con el nazismo presentándolo como un caso de cobardía comprensible y mero instinto de conservación ante la muy temible dictadura nazi, pero las evidencias de que las simpatías del filósofo por el nazismo se manifestaron antes de 1933 son incontestables. En todo caso, tampoco se entiende bien porqué la cobardía y el oportunismo hablarían mejor de una persona que el fanatismo político y la intolerancia. Con frecuencia, los cobardes y los oportunistas acaban causando más daño que los fanáticos, los segundos no podrían ejecutar muchos de sus propósitos sin la pasividad de los primeros. La conducta de Heidegger para con sus colegas no arios o ideológicamente alejados del partido nazi fue, en palabras de George Steiner, mezquina pero de una manera esporádica. A la postre, no es fácil discriminar cuánto había en él de nazi convencido y cuánto de oportunista o precavido. Hay testimonios personales creíbles de que Heidegger hacía explícito su nazismo incluso cuando no sería necesario hacerlo por mero instinto de supervivencia. En 1936, Heidegger visita en Roma a su antiguo alumno Karl Lowith refugiado huido del antisemitismo galopante en Alemania. Para visitar a su alumno judío, el maestro "creyó oportuno presentarse llevando en la solapa la insignia nazi con la cruz gamada, muestra de delicadeza que Lowith apreció en lo que valía” (Savater, 2000: 83). Como resume Savater, "en Heidegger hay más cosas que el nazismo, pero también está $-y$ fundamentalmente- el nazismo" (2000: 82). Lo que parece indudable es que de ningún modo $y$ en ningún momento defendió a su antiguo maestro y protector. Retiró la dedicatoria a Edmund Husserl de su libro "Sein und Zeist" (Ser y Tiempo); años después lo justificaría argumentando que las autoridades nazis no hubieran permitido reeditar la obra si mantenía esa dedicatoria. Cuando Husserl fallece en 1938,
Heidegger no envió ninguna nota de pésame a la viuda judía de su antiguo maestro.

En 1953, Heidegger reedita su Introducción a la Metafísica cuyo origen eran unas conferencias de 1935. Mantiene en esta reedición de 1953 que: "Las obras que actualmente se ofrecen por ahí como si fueran la filosofía del nacional-socialismo, pero que no tienen nada que ver con la profunda verdad y grandeza de este movimiento..." (Steiner, 1986: 158). Incluso ocho años después del final del nazismo Heidegger continuaba reafirmando la profunda verdad y grandeza de aquella ideología terrible.

Si el caso personal de Heidegger o la circunstancia histórica del nazismo pudieran parecer un tanto alejados en el tiempo, podríamos hallar desafortunadamente otros ejemplos de abdicación ética en quienes por su profesión parecen menos justificados a avalar las violaciones colectivas de derechos humanos. El silencio cómplice de muchos intelectuales occidentales autodenominados de izquierda y progresistas con el estado de los derechos humanos durante cuarenta años en la Europa oriental ha sido reiteradamente criticado. Más cercano a nosotros, tenemos el conflicto de los Balcanes o disolución de la antigua Yugoslavia donde se revivieron los fantasmas de las limpiezas étnicas que se creían enterrados tras 1945. Que los intelectuales de las propias etnias balcánicas adoptaran en muchos casos posturas partisanas, justificadoras de la violencia, en un conflicto en el que todas las partes la ejercieron brutalmente contra indefensas poblaciones civiles, casi parecería humanamente comprensible en medio de aquella locura colectiva. Menos comprensible parece que el novelista y cineasta austriaco Peter Handke más allá de su oposición a los bombardeos de la OTAN sobre la servia de Milotsevich que pudieran tener una justificación humanitaria, defendiese y pronunciase el elogio en los funerales del político servio cuya responsabilidad en genocidios étnicos difícilmente podía ignorar.

\section{TOMAR PARTIDO EN TIEMPOS SIN RUMBO}

Cuando Russell primero (The Practice and Theory of Bolshevism, 1920) y Gide después 
(Voyage au Retour de l'URSS, 1936) vieron con sus propios ojos la represión comunista en la Unión Soviética, tomaron el partido de denunciarla explícitamente. Sartre, Neruda y Aragon no queriendo ver la inhumanidad del estalinismo también estaban tomando partido. Aceptaban unos medios que sabían repugnantes, lo hacían en aras a un fin que suponían alcanzable e idílico. Cuando esa apisonadora de toda libertad individual que era el nazismo tomó el poder absoluto a partir de 1933, Mann, Einstein y Popper abandonaron Alemania los dos primeros y Austria el tercero, quienes como Heidegger optaron por vivir y medrar bajo la cruz gamada también estaban tomando partido. En la Francia ocupada por los nazis, artistas como Picasso o Cocteau pudieron refugiarse en una cierta ambigüedad silenciosa, eran maestros de su arte pero no intelectuales o en el sentido que damos aquí a tales términos. En esa misma Francia ocupada donde el gobierno de Pétain entregaba niños judíos a la gestapo, Celine aplaudía ese antisemitismo colaboracionista de Vichy mientras Malraux, Mauriac y Camus combatían desde la clandestinidad a la peste racista, todos ellos tomaban necesariamente partido. Pero los acontecimientos se suceden, es la característica de la historia empeñada en contradecir a algunos neoconservadores que anunciaban el fin de la misma hace no tanto tiempo. De pronto, el escenario ante el cual se tomó públicamente una posición cambia sustancialmente. Los mismos tanques rusos que en 1945 contribuyeron decisivamente a liberar a Europa del nazismo acorralando a Hitler en su búnker y conquistando Berlín, aplastaban en 1956 al desarmado pueblo húngaro que reclamaba democracia. ¿Era posible seguir considerando liberadores del género humano a esos tanques? Camus y Koestler gritarán rotundamente que no, Sartre y Neruda guardarán silencio. Con frecuencia, diversos intelectuales compartirían un posicionamiento que sentían como claro imperativo ético ante una situación dada: la ocupación nazi de Europa por ejemplo. Posteriormente, una nueva situación vendría a demandar una nueva toma de partido: las guerras de descolonización por citar otro ejemplo. Unidos en el mismo combate contra el ocupante nazi y sus colaboracionistas de Vichy, Sartre y Camus protagonizarán poco más de una década después un fuerte enfrentamiento respecto a la guerra de independencia argelina, arrastrando a sus seguidores que esgrimirán a Camus contra Sartre y viceversa. Bertrand Russell, con sus 97 años de dilatada existencia comprometida en el combate permanente por la libertad contra toda forma de intolerancia y superstición, necesariamente se verá forzado a tomar partido ante situaciones muy cambiantes. Será pacifista activo contra la participación de Inglaterra en la I Guerra Mundial (expulsado por ello de su cátedra en Cambridge y encarcelado unos meses) pero partidario de oponerse como fuera necesario a la ocupación nazi de Europa. Creía que el triunfo de Alemania en la I Guerra (19141918) no hubiera cambiado sustancialmente el sistema de libertades $y$ derechos que poco a poco Europa iba dándose, nada decisivo estaba en juego en aquella conflagración que consideraba una "guerra de prestigio" (Russell, 1915: 5). Por el contrario, el triunfo de la Alemania nazi en la II Guerra (19391945) hubiera acabado con la civilización en Europa tal y como la entendemos, será esta una "guerra de principios" (Russell, 1915: 5). Pacifista convencido en la Primera Guerra Mundial, belicista resignado en la Segunda, nuevamente volvería a un pacifismo radical en sus posicionamientos durante la guerra fría $y$ ante la guerra de Vietnam. Setenta años de continuada actividad pública atravesando un siglo horrorosamente fecundo en "tempestades de acero", utilizando la expresión de Ernest Junger con la que este titularía una novela autobiográfica de la Primera Guerra (Magris, 2001: 233), obligaron a Russell a tomar posturas en circunstancias harto cambiantes con muy diversos riesgos para nuestra civilización. ¿Hubiera sido razonable exigir a Russell coherencia si por tal entendemos mantener una posición inamovible durante setenta años?

\section{DE LA HUMANIDAD A LA NACIONALIDAD: EL PELIGRO IDENTITARIO}

Las guerras civiles que desmembraron la antigua Yugoslavia a finales del pasado siglo 
revivieron en Europa horrores que se creían enterrados por siempre entre los escombros dejados por la II Guerra Mundial. Himmler pareció revivir por un momento en los Balcanes y las expresiones "genocidio" y "limpieza étnica" recuperaron una vigencia que nadie hubiera previsto pocos años antes, al menos no en Europa. Quizás resignadamente en África, donde procesos de descolonización geográficamente arbitrarios encerraron en un mismo territorio a etnias secularmente enemistadas. El papel de muchos intelectuales, hemos citado el ejemplo del austriaco Peter Handke pero habría una amplia nómina que citar en la que cada etnia, cada facción, tuvo nutrida representación, no fue en absoluto ejemplar ni constructivo por decirlo en una forma suave. Pocos años después, en la Universidad de Varsovia en un debate sobre literatura y fronteras, esas fronteras que nacieron un poco por todas partes tras la desmembración del bloque soviético, nos recuerda Claudio Magris que alguien comentó a propósito de las fronteras ideológicas y geográficas "que a los políticos les corresponde fijar con claridad estas últimas en relación con los Estados y a los intelectuales mantenerlas abiertas en la mente $y$ en el corazón de los hombres" (Magris, 2001: 35). Lamentablemente, no ha sido esta tarea aperturista de mentes la ocupación primera de la mayoría de los intelectuales. Acabado, aparentemente porque en la historia de las utopías se producen en ocasiones inesperadas resurrecciones, el tiempo de esas ideologías absolutas y proféticas cual religiones laicas y que tan diafanamente denunciara Karl Popper en La miseria del historicismo (1957; 1973), no pocos intelectuales en los últimos años del pasado siglo parecen haberse vuelto aparentemente desengañados de la Humanidad (tan frustrante ella en lo tocante al cumplimiento de profecías históricas) hacia la nacionalidad. ¿Cabría hablar, parafraseando a Popper, de una "miseria del nacionalismo"? Lo cierto es que un poco por todas partes, desde las reivindicaciones de las autodenominadas "naciones sin estado" europeas a un cierto "revival" indigenista en Latinoamérica que es difícil discriminar qué contiene de auténtica compensación de injusticias seculares de origen racista y qué de mero folclore, se asiste a la coronación de un nuevo "ídolo": la identidad. El problema con los ídolos es que acaban exigiendo sacrificios, con preferencia sacrificios humanos. La identidad conlleva aparejada la ilusión de un destino para quienes la comparten, y como oportunamente advierte Amartya Sen (2007) la identidad acaba fácilmente emparejada con la violencia, la violencia contra el vecino al que se ve como obstáculo al cumplimiento de dicho destino.

El sentido de identidad puede excluir, de modo inflexible, a mucha gente mientras abraza cálidamente a otra. La comunidad bien integrada en la que los residentes hacen instintivamente cosas maravillosas por los demás con prontitud y solidaridad puede ser la misma comunidad en que se arrojan ladrillos a las ventanas de los inmigrantes que llegan al lugar.

(Sen, 2007: 25).

En 1943, en su exilio en una universidad neozelandesa huyendo del peor delirio identitario conocido hasta el momento, el nazismo, Karl Popper concluía La sociedad abierta y sus enemigos $(1945 ; 1981)$ que tras ser rechazado por varias editoriales será publicado en 1945. El ámbito editorial académico de la época no se mostraba bien dispuesto a acoger la acusación de Popper señalando al Platón de $L a$ República como el antecedente primero de los totalitarismos historicistas del momento, el nazismo y el comunismo estalinista, (piénsese que estamos en el año en que concluye la Segunda Guerra Mundial, la más dura prueba sufrida hasta el momento por la humanidad, las heridas están abiertas y con ellas las susceptibilidades sobre responsabilidades históricas $y$ morales). Curiosamente, ese mismo año de 1945 publica Bertrand Russell su Historia de la Filosofía Occidental $(1945 ; 1984)$, sin conocimiento en ese tiempo de la existencia de Popper ni de su obra, Russell viene a coincidir en su juicio negativo sobre la influencia del platonismo en la historia occidental. El desprecio a la realidad por comparación con algún hipotético ideal del que la primera es una pobre copia a superar (platonismo) y la pretensión historicista 
de conocer las leyes que determinan y explican tal realidad (hegelianismo y marxismo) habrían llevado al mundo al horror que ese mismo año de 1945 parecía alcanzar su cenit combinando las imágenes de los campos de exterminio descubiertos en la Europa ocupada por los nazis y la bomba de Hiroshima. Los intelectuales, los "maestros" del momento, con honrosas excepciones (el Thomas Mann de su segunda época tras la I guerra mundial, André Gide, Herman Hesse, Bertrand Russell, pocos más), no habían contribuido a evitar que la humanidad llegase a tales niveles de horror, seguramente no está en la capacidad de un intelectual influir directamente en los acontecimientos, sino que ni siquiera habían advertido de tales amenazas o, lo que era peor, en algunos casos se habían erigido en defensores de una u otra ideología que inexorablemente conducían a tales horrores. Como decíamos en la introducción, el rol de los intelectuales en la vida pública no parece importante ya en los inicios de este siglo XXI, quizás esto no sea algo a lamentar visto lo acontecido en el siglo anterior y que apenas hemos esbozado aquí en muy pocas páginas. Sin embargo, la ausencia de los intelectuales en nada supone ausencia de complejos problemas que desafían hoy la inteligencia humana. La explosión demográfica en las zonas más depauperadas del planeta, el agotamiento de recursos no renovables, un aparente cambio climático sobre el que los científicos cada vez parecen dudar menos, el hambre inexplicable de gran parte de la humanidad cuando somos técnicamente capaces de alimentar al mundo. "Somos mucho más que capaces de alimentar al mundo entero. El problema está solucionado por parte de la técnica, no de los economistas" (Popper, 1995: 244). Sin olvidar un resurgimiento de la intolerancia religiosa con un retorno a fundamentalismos de los que cabe esperar lo peor para el futuro de nuestras libertades $y$ ese nuevo historicismo excluyente que constituyen los múltiples nacionalismos identitarios. Son tan solo algunas de estas bombas de relojería que la humanidad tiene ante sí y cuya desactivación exige una capacidad para el consenso en la resolución de problemas complejos que no ha caracterizado frecuentemente a nuestra especie. Karl Popper, quien "creyó siempre que la vida es un proceso de solución de problemas" (Magee, 2000: 100) y que no se tuvo ni fue tenido por un "maestro" en el sentido desmedido del adjetivo, pudiera ser un consejero adecuado a la complejidad del presente $y$ ante los problemas que la humanidad y cada una de las sociedades que la componen habrán de resolver. Si las "ideologías duras", probablemente Popper preferiría el calificativo de "cerradas", y los intelectuales que las sirvieron ensombrecieron el siglo Xx, ¿nos quedan referentes más allá de nuestras necesidades cotidianas al comienzo de este nuevo siglo?

\section{UNA INGENIERÍA SOCIAL BENEVOLENTE}

Popper fue ante todo un filósofo de la ciencia, un metodólogo. El método científico aplicado a la resolución de problemas en CC. naturales, denominado "hipotético-deductivo", se fundamenta en la comprobación de hipótesis deducidas de un conocimiento previo $y$ que se proponen respecto a un problema de investigación. Si tales hipótesis no son corroboradas por los datos se abandonan, proponiendo nuevas hipótesis sobre el problema que a su vez se someterán a nueva comprobación empírica (método crítico de ensayo y error). Una teoría cuyos supuestos básicos no puedan ser traducidos a hipótesis comprobables empíricamente, como es el caso del psicoanálisis, la astrología, el materialismo histórico o la supremacía racial, no pertenece al terreno del conocimiento científico (Medawar, 1997: 126-136). Científico es, por tanto, el conocimiento que tan solo puede sustentarse en la acumulación de hipótesis corroboradas hasta el presente aunque siempre susceptibles de ser falseadas en el futuro. Probablemente, ningún filósofo de la ciencia haya insistido tanto como Karl Popper en esta exigencia para todo conocimiento que se pretenda racional de estar abierto permanentemente a la corroboración empírica de sus supuestos, a que estos puedan ser falseados por la realidad en cualquier momento ("falsacionismo"). A diferencia del científico, que tan solo tiene "hipótesis confirmadas hasta el momento", los intelectuales han pretendido tradicionalmente 
tener "certezas deducidas de una teoría", es decir un conocimiento apriorístico de la realidad que ni tan siquiera necesita mirar detenidamente a esa realidad, al igual que los cardenales romanos no necesitaban mirar por el telescopio de Galileo porque habían leído a Aristóteles. Tal ha sido el esquema mental de los historicismos y hemos repasado brevemente algunas de las catástrofes que estos han provocado en el pasado siglo. El derrumbe de las economías del llamado "socialismo real" en las dos últimas décadas del pasado siglo, habría desempeñado el rol de "experimento crítico" del marxismo, seguramente el historicismo más fuerte del siglo Xx. Hay razones para temer que modernos "historicismos menores", tales como los nacionalismos identitarios a los que aludíamos en el apartado precedente, estén tomando el relevo para llenar un "vacío sentimental de utopías". Hay razones para temer que nuevamente se sacrificarán recursos, tiempo y vidas a nuevas utopías y con ello se retrasará en el mejor de los casos la solución de los problemas reales.

En el propósito de que las sociedades se beneficien de la eficacia limitada pero probada en la solución de problemas del método científico. Con el objetivo no menos importante de que estas sociedades tengan capacidad de rectificar en tiempo adecuado sus opciones erróneas, que tantos recursos y vidas humanas han costado cuando se pusieron en práctica utopías historicistas en un pasado no tan lejano. Se propone aquí la sustitución de las ideologías por el método científico en la solución de problemas sociales, con ello se está proponiendo necesariamente la recuperación de una democracia original en una sociedad abierta. Las sociedades abiertas son las únicas propensas a la solución racional de problemas (Magee, 2000: 101), son las únicas en las que es factible la propuesta libre de hipótesis, la corroboración de las mismas y el abandono de las que no se vean razonablemente confirmadas en la solución real del problema que se trate. La democracia originalmente, como recordaba Erich Fromm,

no pretendía ser un régimen de consentimiento manipulado, sino un régimen en que cada ciudadano participase activa $y$ responsablemente en las decisiones, un régimen en el que al ciudadano se le mantuviera realmente informado y no equivocado (Fromm, 1993: 18).

No es por azar que las pocas sociedades democráticas existentes en la actualidad, $y$ aún sería discutible hasta qué punto son sociedades realmente abiertas a la libre expresión, a la libre participación en igualdad de condiciones $y$ a la responsabilidad compartida en la toma de decisiones, son las que ofrecen mayor calidad de vida a sus miembros porque son las que van aproximándose a la solución de sus problemas mediante sucesivos ensayos y eliminación de errores. Se trate del desempleo, la migración, la protección de los sectores más desfavorecidos de la población, la dicotomía castigo/rehabilitación de los comportamientos delictivos o la dicotomía calidad/masificación de la educación. Se trate de cualquiera de los muy complejos problemas inherentes a la convivencia en las sociedades modernas, nunca se alcanzará una imposible solución permanente de tales problemas pero se aproximarán sucesivamente a soluciones necesariamente temporales de los mismos aquellas sociedades abiertas al libre contraste de hipótesis y a la alternancia democrática en el poder de corroborar unas $\mathrm{u}$ otras hipótesis para determinado problema. La vía de la solución a los problemas sociales está, retomando de nuevo palabras de Erich Fromm, "en invertir la tendencia burocrática $y$ atender a que las ideas, las sugerencias y las demandas vayan de abajo hacia arriba, en vez de decir que los burócratas de arriba lo tienen todo previsto" (Fromm, 1993: 18). Se conoce como "ingeniería social" este procedimiento de abordar los problemas sociales con la metodología científica. Es decir, proponer unas hipótesis respecto a uno $\mathrm{u}$ otro problema, $\mathrm{y}$ comprobar empíricamente los efectos de tales hipótesis. Los resultados empíricos conducirán a mantener o ajustar las hipótesis. Otras veces, la ineficacia de las hipótesis hará que se desechen abordando nuevamente el problema, desde otros supuestos. "El ingeniero social ha de tener presente que solo aprendemos de nuestros errores, $y$ por eso debe adoptar una 
postura crítica con respecto a sus propuestas de composturas o reformas parciales, comparando los resultados obtenidos con los esperados" (Perona, 1993; 137). El ingeniero social, a diferencia del político o el intelectual de otros tiempos, no pretende tener un conocimiento apriorístico de las soluciones que demandan los problemas de las sociedades. No tiene una ideología en sentido estricto, tiene supuestos, hipótesis, respecto a posibles soluciones limitadas a problemas concretos.

Comenzábamos hablando de maestros, quienes fueron tomados como grandes referentes morales e intelectuales, de su ausencia o muy disminuida influencia en la opinión pública actual, y concluimos hablando de ingenieros aunque sean "sociales". Alguien podría lamentar, asociando la ingeniería con el prosaico mundo de las fábricas y la filosofía con las cumbres elevadas del intelecto abstracto, cierta "rebaja de horizontes". Recordemos una vez más que las ideologías cerradas que llamamos aquí historicismos, adoptando el término popperiano, han inspirado a lo largo del pasado siglo los mayores horrores protagonizados por el hombre. La conquista del "espacio vital" necesario a la expansión de "una raza superior" o la construcción de un paraíso sin clases, utopías a las que el sacrificio de millones de vidas pareció a no pocos en su momento "un precio justificable", son ideas que no cabrían en la planificación limitada y fragmentada que caracteriza a la ingeniería. Hay que ser un "intelectual" hegeliano, nietzscheano o marxista para predicar tales pesadillas colectivas. Una segunda crítica, merecería mayor consideración, la frialdad o falta de humanidad que puede asociarse mentalmente con la práctica de la ingeniería. Ciertamente, cuando hablamos de "ingeniería social" nunca podríamos perder de vista que hablamos de seres humanos. Es por esto que al término "ingeniería social" asociábamos en el título del presente apartado el calificativo "benevolente", etimológicamente la aplicación de una buena voluntad a lo que se hace. Han sido precisamente los historicismos, los sistemas filosóficos aplicados a la política, los que reiteradamente han violentado el imperativo moral kantiano de tomar a cada hombre o mujer como un fin en sí mismos y no como un medio para nuestros fines, han sacrificado millones de personas a sus fines. Por el contrario, desde la perspectiva más cotidiana, más terrena, si se quiere incluso más prosaica, de la ingeniería social que aquí propugnamos es desde donde al otro lo percibimos más próximo y semejante a nosotros mismos, precisamente porque no lo excluimos con una etiqueta ideológica (es un comunista, es un capitalista, es un mestizo, etc.). Desde esta proximidad a los otros, abolidas las distancias ideológicas que tanto contribuyen a cosificar al otro, es de donde ya no tenemos excusa para la manipulación y la crueldad, ya no queda instancia metafísica superior ni utopía futurista que nos justificase por causar dolor innecesario. El propio Karl Popper en una de sus últimas entrevistas ya con 90 años lo resumía expresamente: "Lo mejor es en un sentido muy terminante lo que menos violencia encierra, aquello que reduce el sufrimiento, el sufrimiento innecesario" (1995: 249).

\section{REFERENCIAS}

Berlin, I. Cuatro ensayos sobre la libertad. Madrid. Alianza Editorial. Alianza Universidad, 2000: 75.

Fromm, E (1993). Ética y política. Obra póstuma 3. Traducción de Ethik und politik. Antworten auf aktuelle politische Fragen 94. Barcelona: Paidós Studio, Weinheim, eutschland. Beltz Verlag 1990.

Magee, B. Popper. $2^{\text {a }}$ ed. México D. F: Colofón S. A. 2000.

Magris, C. Utopía y desencanto: Historias, esperanzas e ilusiones de la modernidad. Barcelona: Editorial Anagrama. Colección Argumentos, 2001.

Medawar, P. "Nuevos comentarios sobre el psicoanálisis". P. Medawar. El extraño caso de los ratones moteados y otros ensayos sobre ciencia. Cap. 11. Barcelona: Grijalbo Mondadori, colección Drakontos, 1997: 126-136. Traducción de la edición inglesa The strange case of the spotted 
mice an other essays on science. Oxford University Press. Oxford GB, 1996.

Pais, A. J. Robert Oppenheimer. A life. New York: Oxford University Press, 2006.

Perona, A. J. Entre el liberalismo y la socialdemocracia. Popper y la "Sociedad Abierta”. Barcelona: Anthropos. Colección Pensamiento Crítico/Pensamiento Utópico 76. 1993.

Popper, K. The open society and its enemies. 2 vols. Londres: Routledge and Kegan Paul, 1945. Traducción española: La sociedad abierta y sus enemigos. Buenos Aires: Paidós, 1981.

The poverty of historicism. London: Routledge and Kegan Paul, 1957. Traducción española: La miseria del historicismo. Madrid: Alianza Editorial, 1973.

. Alles leben ist Problemlösen. Uber erkenntnis, geschichte und Politik. Piper. Munich, 1994. Traducción española: La responsabilidad de vivir. Escritos sobre politica, historia y conocimiento. Barcelona: Paidós. Colección Estado y Sociedad 31. 1995.

Entrevista publicada en Der Spiegel, Abril 1992. Recogida en: Karl Popper. La responsabilidad de vivir.
Escritos sobre politica, historia $y$ conocimiento. Barcelona: Paidós. Colección Estado y Sociedad 31. 1995: 239-249.

Russell, B. "The ethics of war". International Journal of Ethics, enero, 1915.

. (1945). A history of western philosophy. Traducción española: Historia de la filosofía occidental. 2 vols. Madrid: Espasa Calpe, 1984.

Savater, F. Humanismo impenitente. $2^{\text {a }}$ ed. Barcelona: Editorial Anagrama. Colección Argumentos. 2000.

Sen, A. Identidad y violencia. La ilusión del destino. Buenos Aires: Editorial Katz. Colección Discusiones. 2007. De la edición original Identity and violence. The illusion of destiny. New York: Norton \& Company Ltd., 2006.

Steiner, G. Heidegger. México DF.: Fondo de Cultura Económica. Col. Breviarios 347. 1986. De la edición original en Inglés, Heidegger, 1978.

- Lecciones de los maestros. México DF.: Ediciones Siruela. Fondo de Cultura Económica, 2004. De la edición original Lessons of the Masters, Steiner, 2003. 